\title{
Inhibition of MTA1 by ERa contributes to protection hepatocellular carcinoma from tumor proliferation and metastasis
}

\author{
Lei Deng ${ }^{1 \dagger}$, Hui Yang ${ }^{2 \dagger}$, Junwei Tang ${ }^{1}$, Zhe Lin ${ }^{1}$, Aihong Yinn', Yun Gao ${ }^{1}$ Xuehao Wang ${ }^{1}$, Runqiu Jiang ${ }^{1 *}$
} and Beicheng Sun ${ }^{1 *}$

\begin{abstract}
Background: Although expression of MTA1 inversely correlates with the nuclear localization of ERa, the effect and molecular mechanism of ERa regulation of MTA1 remain unknown.

Methods: Quantitative real-time PCR and western blot analyses were used to measure levels of MTA1. The effect on HCC cell proliferation and invasion was assessed by EdU incorporation assays and Transwell, respectively. ShRNA and dual-luciferase assays were used to investigate the regulatory relationship between MTA1 and ERa in cell lines.

Results: We found that MTA1 gene regulation by ERa may be influenced by nuclear corepressors. The MTA1 promoter has three functional ER-element half-sites that lead to decreased MTA1 transcription and expression. ERa overexpression suppressed the proliferation and invasion of hepatocellular carcinoma cells (HCC). In addition, overexpression of MTA1 attenuated ERa-mediated suppression of the proliferation and invasion of HCC cells and tumor formation in vivo. These results suggested feedback regulation between ERa and MTA1. In summary, our results demonstrated that ERa suppressed proliferation and invasion of human HCC cells through downregulation of MTA1 transcription.
\end{abstract}

Conclusions: Our study is an improved description of the mechanisms of the suppressive effect of ERa on HCCs, adding understanding to the gender disparity of HCC progression.

Keywords: ERa, MTA1, ER element, Corepressor, HCC

\section{Introduction}

Many studies have explored the expression levels of MTA family members, especially MTA1, in human cancers [1]. MTA1 gene expression correlates with cancer progression and degree of invasion for hepatocellular carcinoma (HCC) and other carcinomas [2-5]. Of $20 \mathrm{HCC}$ specimens with vascular invasion, 19 (95 \%) displayed strong MTA1 expression. Overexpression of MTA1 also significantly correlates with large tumor size [6]. Increased MTA1 expression in HCC correlates with larger tumors, perinodal extension, and microvascular invasion [7]. High expression

\footnotetext{
* Correspondence: jiangra@njmu.edu.cn; sunbc@njmu.edu.cn

†Equal contributors

${ }^{1}$ Liver Transplantation Center of the First Affiliated Hospital and State Key Laboratory of Reproductive Medicine, Nanjing Medical University, Nanjing, Jiangsu Province, P.R. China

Full list of author information is available at the end of the article
}

of the MTA1 gene is suggested to be a prognostic indicator after curative hepatectomy for $\operatorname{HCC}[2,3]$. Other data indicate that MTA1 is closely associated with microvascular invasion, frequent postoperative recurrence, and poor survival of HCC patients, especially those with $\mathrm{HBV}$-associated HCC [7]. MTA1 is overexpressed in patients with invasive $\mathrm{HBV}$ associated HCC. MTA1 overexpression is associated with shorter survival of patients with $\mathrm{HBV}$-associated HCC after curative resection [8]. Previous reports also indicate that large tumors are more common in estrogen receptor (ER)-negative HCC. Furthermore, in a normal hepatocyte cell line, MTA1 expression was absent or minimal, whereas ER $\alpha$ was present in the nucleus [9]. Expression of MTA1 inversely correlates with ER $\alpha$ nuclear localization [6]. 
Several lines of evidence suggest involvement of sex hormones and their receptors in liver carcinogenesis. $E R \alpha$ is expressed in the liver of healthy individuals and patients with chronic hepatitis and HCC [10]. ER-positive HCC is malignant and has a better prognosis than ERnegative HCC [9]. HCC occurs more often in men than women by a ratio that ranges from 2:1 to 11:1 in several cohort reports [11]. Estrogen, which exerts its biological function through ERs, inhibits HBV replication [12]. A previous study showed that, in women, the risk of HCC is inversely related to age of menopause and number of full-term pregnancies [13]. This finding is consistent with animal studies showing that ovariectomy increases susceptibility to HCC in female mice [14]. ER is significantly downregulated in HCCs, both by immunohistochemistry staining and receptor-binding assays [15-18]. The steroid hormone $17 \beta$-estradiol (E2) is important for controlling the expression of genes involved in a variety of biological processes including reproduction, development, and HCC progression. ER $\alpha$ is the major ER in the mammary epithelium. Ligand-activated ER $\alpha$ translocates to the nucleus, binds to estrogen response elements (EREs) in target gene promoters, and stimulates or represses gene transcription $[19,20]$. The consensus ERE is a 13-bp palindromic sequence containing two inverted repeats of 5'-GGATC-3' separated by three base pairs. ER $\alpha$ binds to nonperfect or half ERE sequences, particularly in the context of appropriate flanking sequences [21]. Corepressors are crucial regulators of ER $\alpha$-mediated action and they might inhibit HCC development. An increasing number of ER $\alpha$ corepressors are being reported [22]. A previous study found that overexpression of ER $\alpha$ decreases PPAR $\gamma$ expression at the transcriptional and translational level in a ligand-dependent manner [23]. Among ER corepressors, NCoR and SMRT are widely characterized molecules implicated in transcriptional silencing in the absence of ligands [24]. Given the importance of ER $\alpha$ in $\mathrm{HCC}$, the role of ER $\alpha$ corepressors in the molecular mechanism of ER $\alpha$ activity needs to be better understood.

In this study, we investigated the effects of ER $\alpha$ on three half-ERE sequences of the MTA1 promoter in HCC. Proliferation and invasion assays and animal model experiments provided evidence that inhibition of MTA1 by ER $\alpha$ is important for attenuating HCC progression. These findings are an improved characterization of the molecular events underlying the gender inconsistency of HCC progression.

\section{Materials and methods Ethics statement}

All animal work was conducted under the institutional guidelines of Jiangsu Province and approved by the Use Committee for Animal Care.

\section{Chromatin immunoprecipitation}

ChIP assays were performed by Pierce ${ }^{\mathrm{mm}}$ Agarose ChIP Kit (Thermo Fisher Scientific, Rockford, USA). HepG2 cells were treated with formaldehyde and incubated for 10 min to generate DNA-protein cross-links. Cell lysates were then sonicated to generate chromatin fragments and immunoprecipitated with ER $\alpha$ antibody or IgG as control. Precipitated chromatin DNA was recovered and analyzed by PCR. The PCR primers were: sense, 5'-CGCACGACCACCTGTCCA-3', and anti-sense, 5'-G CCCTTCCACCAGAACCC-3'. The acquired DNA was resolved on a $2 \%$ agarose gel and stained with Goldview.

\section{Real-time PCR}

RNAs were extracted from cells using TRIzol (Invitrogen, California, USA) kit according to the manufacturer's instructions. Subsequently, total RNA was reverse transcribed using SuperScript III reverse transcriptase (Invitrogen, California, USA). Real-time PCR was then performed in ABI PRISM7500 system (Applied Biosystems, California, USA), according to the manufacturer's instructions. The expression level of each gene was normalized by GAPDH and reported as relative levels. The primers sequences for real-time PCR were obtain from the PrimerBank online. The PCR primers were: MTA1, sense, 5'-ACGCAACCCT GTCAGTCTG-3', and anti-sense, 5'-GGGCAGGTCCAC CATTTCC-3'; GAPDH, sense, 5'-GGAGCGAGATCCCT CCAAAAT-3', and anti-sense, 5'- GGCTGTTGTCATAC TTCTCATGG-3'.

(http://pga.mgh.harvard.edu/primerbank/).

\section{Dual luciferase reporter assay}

The MTA1 gene $-600 \sim-1$ region was cloned into the pEZX-PG04 with Gaussia Luciferase (GLuc) and Secreted Alkaline Phosphatase (SEAP) labeled, named pEZX-PG04-MTA1 (GeneCopoeia, Guangzhou, China). For transient transfection, the plasmids were transfected into cells directly by lipofectamine 2000 (Invitrogen, USA). Secrete-Pair ${ }^{\text {th }}$ Dual Luminescence Assay kit (GeneCopoeia, Guangzhou, China) was performed $48 \mathrm{~h}$ after transfection according to the manufacturer's protocol and detected with a Fluoroskan microplate reader (Thermo Labsystems, Helsinki, Finland). The activities of Gaussia Luciferase (GLuc) and Secreted Alkaline Phosphatase (SEAP) from cell culture medium were analyzed using a Secrete-Pair ${ }^{\text {na }}$ Dual Luminescence Assay kit according to the manufacturer's instructions. Calculate the ratio of luminescence intensities (RLU, Relative Light Unit) of the GLuc over SEAP. Compare the normalized GLuc activity (GLuc/SEAP ratio) of all samples.

\section{Lentivirus production and infection}

pLV-GFP vector system were constructed for overexpression of ER $\alpha$ and MTA1; pLL3.7-GFP vector system 
were constructed for ER $\alpha$ shRNA. The shRNA sequences were: 5'-AACGGCATGGAGCATCTCTACATTCAAGAG ATGTAGAGATGCTCCATGCCTTTTTTC-3' [25] and 5'AACTGGTTTACATGTCGACTAATTCAAGAGATTAG TCGACATGTAAACCTTTTTTTC-3' for ER $\alpha$ and scramble, respectively. All constructs were sequence-verified. Details are available on request. Lentivirus of ER $\alpha$, MTA1, and $E R \alpha$ shRNA were derived from our previous protocols [26]. The HCC cell lines HepG2 and Hep3B were obtained from Chinese Academy of Sciences and maintained in DMEM medium (Life Technologies, Carlsbad, CA, USA) supplemented with $10 \%$ fetal bovine serum, 100 units $/ \mathrm{ml}$ penicillin, and $100 \mu \mathrm{g} / \mathrm{ml}$ streptomycin (Invitrogen, Carlsbad, CA, USA) in a humidified $5 \% \mathrm{CO} 2$ incubator at $37{ }^{\circ} \mathrm{C}$. The Hep3B-ER $\alpha$, HepG2-shER $\alpha$, and Hep3B-ER $\alpha /$ MTA1 cells were generated from our previous protocols [26].

\section{Western blotting}

Whole cells were washed in PBS and lysed in RIPA lysis buffer supplemented with protease inhibitor cocktail (Roche, Mannheim, Germany). Total protein was quantified using a BCA Protein Assay Kit (Beyotime, Jiangsu, China), and an equal amount of whole cell lysates was resolved by SDS-polyacrylamide gel electrophoresis (PAGE) and transferred to a polyvinylidene difluoride (PVDF) membrane (Millipore, Eschborn, Germany). The blots were blocked in BSA ( $5 \% \mathrm{w} / \mathrm{v}$ in PBS $+0.1 \%$ Tween 20) for $1 \mathrm{~h}$ at room temperature. The following primary antibodies were used according to the manufacturer's instructions. Antibodies against ER $\alpha$, MTA1, and $\beta$-actin were purchased from Santa Cruz Biotechnology (Santa Cruz, CA). The appropriate secondary antibodies (Santa Cruz Biotechnology, Santa Cruz, CA, USA) were used at 1:1000-1:2000 (v/v) dilutions in PBS + 0.1\% Tween 20 for $1 \mathrm{~h}$ at room temperature, and the signals were revealed using ECL kit(Thermo Scientific Pierce, Thermo Fisher Scientific, Rockford, USA). The cells were induced with $10 \mathrm{nM}$ and $100 \mathrm{nM} 17 \beta$-estradiol (E2) for $24 \mathrm{~h}$.

\section{CCK-8 assay}

Cell proliferation was measured by using the Cell Counting Kit-8 assay (CCK-8, Dojindo, Japan). Briefly, cells were plated into 96-well plates at a density of $10^{4}$ cells/well with $100 \mu \mathrm{L}$ of culture medium. After adhesion the cells were incubated for 24, 48 and $72 \mathrm{~h}$. At the end of each culture period, $10 \mu \mathrm{L}$ CCK-8 reagent was added to each well and incubated for another $4 \mathrm{~h}$, then the absorbance was measured at $450 \mathrm{~nm}$ wavelength.

\section{EdU assay}

Cells $\left(2 \times 10^{3}\right.$ cells/well $)$ were seeded in triplicate in 96well plates and incubated overnight. Cells were starved in DMEM without FBS for $24 \mathrm{~h}$ and then incubated in DMEM containing 5 \% FBS. Then the EdU (5'-ethynyl-
2 -deoxyuridine) incorporation assay was performed to quantify cell proliferation using the Cell-Light ${ }^{\mathrm{m}}$ EdU DNA Cell Proliferation Kit (Guangzhou Ribobio Co., Ltd, Guangzhou, China) according to the manufacturer's instructions. More than five random fields per well were captured, and IPP 6.0 was used to calculate the percentage of EdU-positive cells in total cells.

\section{Transwell invasion assay}

Cell invasion assays were evaluated using Transwell cell migration plates (Corning, NY, USA) and $8-\mu \mathrm{m}$ pore size Matrigel invasion chambers (BD Biosciences, San Jose, USA) according to the manufacturer's instructions [23-27]. Cells $\left(1.0 \times 10^{4}\right)$ were seeded in serum-free medium into the upper chamber and allowed to invade towards $10 \%$ FBS in the lower chamber. After $24 \mathrm{~h}$ incubation in $37^{\circ} \mathrm{C}$ and $5 \% \mathrm{CO}_{2}$, the cells invaded through the membrane and adhered to the underside of the membrane. Then cells were fixed and stained with crystal violet. The images were acquired by using NIS Elements image analysis software (Nikon, Tokyo, Japan). For the membrane images, we measure the migrated cells using image analysis software ImagePro Plus 6.0 (Media Cybernetics, Bethesda, USA).

\section{Mice model}

Nude mice were purchased from the Vital River Laboratories (Beijing, China). All animals were used in accordance with institutional guidelines and the current experiments were approved by the Use Committee for Animal Care. All cultures used for injection were sub-confluent and were fed the day prior to use. The harvested cell suspension was washed twice by centrifugation in medium containing serum at room temperature and then resuspended in medium without serum at $4{ }^{\circ} \mathrm{C}$ immediately prior to injection. The number of cells $\left(1 \times 10^{5}\right.$ cells $)$ to be injected was suspended in $0.1 \mathrm{ml}$ PBS. The cells were were injected subcutaneously (into groin). The animals were sacrificed 4 weeks after injection. Pictures were recorded with a Nikon d800 digital camera (Nikon, Tokyo, Japan).

\section{Statistical analysis}

All results were expressed as the mean \pm s.d. The Student's $\mathrm{t}$-tests were used to analyse significant differences between samples. All the histogram was evaluated by performing GraphPad Prism, version 4.0 (GraphPad Software, San Diego California, USA). Statistical analyses were performed using Stata. 11.0. $P<0.05$ indicated statistically significant.

\section{Results}

ERa binds the MTA1 promoter and downregulates MTA1 expression

Previous studies show that expression of MTA1 inversely correlates with ER $\alpha$ nuclear localization [6]. We searched 

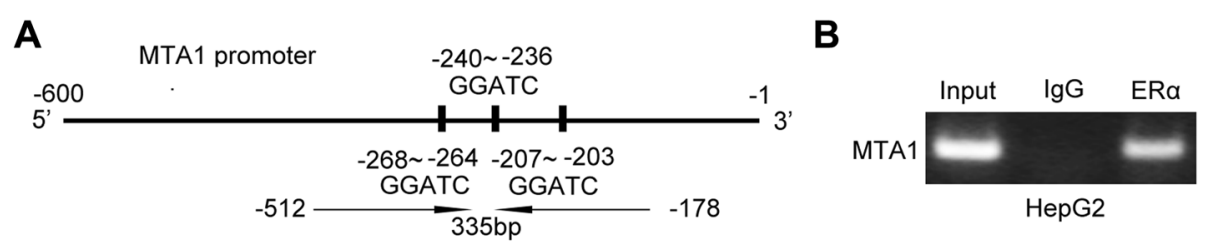

C

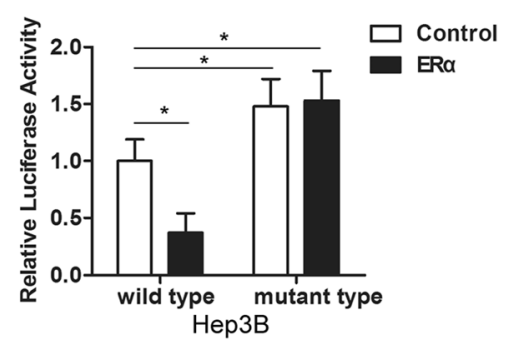

D

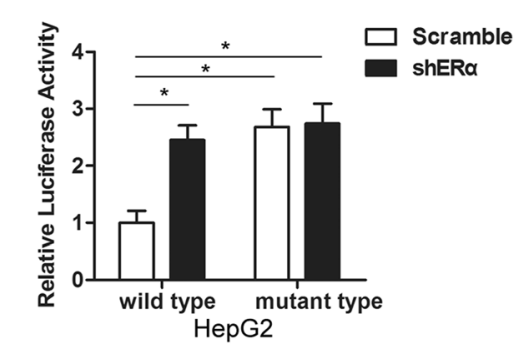

Fig. 1 ERa bound to the MTA1 promoter and downregulated MTA1 expression. a Schematic representation of the MTA1 promoter region with three half-ERE sites. Specific primers amplified -512 to -178 by PCR. b Chromatin immunoprecipitation (ChIP) assays used normal IgG or anti-ERa to identify ERa binding sites on the MTA1 promoter in HepG2 cells. PCR product was 335 base pairs. Three half-ERE sites were deleted from the wildtype MTA1 promoter for the mutant MTA1 promoter. Hep3B (c) and HepG2 (d) cells were cotransfected with luciferase vectors with wildtype or mutant MTA1 promoter or control vector. Results were from three independent experiments and presented as mean \pm SEM. ${ }^{*} P<0.05$ by $t$-test

for EREs within the BMI1 promoter. We found three halfERE sites from -268 to -203 (Fig. 1a). To explore whether ER $\alpha$ assembled a complex on the MTA1 promoter, we performed chromatin immunoprecipitation (ChIP) assays. ER $\alpha$ bound to the region between -512 to -178 that contained the three half-ERE sites (Fig. 2b). To study the regulation of the MTA1 promoter via the ERE half-sites, we generated a wildtype MTA1 promoter fragment and a mutant MTA1 promoter with a deletion from -600 to -1 including the three ERE half-sites. The MTA1 promoter fragments were cloned into a pEZX-PG04 luciferase reporter system. The luciferase activity of wildtype and mutant type MTA1 promoter-luciferase vectors was tested in Hep3B and HepG2 cells. Ectopic overexpression of ER $\alpha$ significantly decreased MTA1 promoter activity in Hep3B cells transfected with the wildtype MTA1 promoter vector but had no effect on cells transfected with the mutant MTA1 promoter vector (Fig. 1c). Transfection with ER $\alpha$ shRNA increased MTA1 promoter activity in HepG2 cells but did not have an effect on the mutant MTA1 promoter (Fig. 1d). Together, these findings indicated that recruitment of ER $\alpha$ to MTA1 promoter chromatin was accompanied by repressed MTA1 promoter activity.

\section{ERa downregulated MTA1 expression in HCC cells}

Hep3B cells were cultured in estrogen-free medium and treated with various concentrations of E2 for $72 \mathrm{~h}$. With E2, MTA1 protein and mRNA decreased (Fig. 2a). Infecting Hep3B cells with an ER $\alpha$ lentivirus at different MOIs resulted in reduction of MTA1 protein and mRNA with increasing lentivirus MOI (Fig. 2b). To further investigate the regulatory effect of $E R \alpha$, we knocked down ER $\alpha$ in HepG2 cells using shRNA lentivirus infection and observed MTA1 expression. As shown in Fig. 2c, knockdown of endogenous ER $\alpha$ significantly increased MTA1 protein and mRNA in a dose-dependent manner.

\section{ERa suppressed the proliferation and invasion of HCC cells}

Based on these results, we hypothesized that the proliferation and invasion effects of MTA1 would be suppressed by ER $\alpha$ in HCC cells. To determine if ER $\alpha$ overexpression suppressed proliferation and invasion, we constructed the cell line Hep3B-ER $\alpha$, which overexpressed ER $\alpha$. CCK-8 proliferation assays revealed that proliferation of Hep3B$E R \alpha$ cells was significantly reduced compared to control Hep3B-vector cells (Fig. 3a). To verify this result, we used 5-ethynyl-2'-deoxyuridine (EdU) in dynamic proliferation assays. Overexpression of ER $\alpha$ impaired the proliferation of Hep3B cells (Fig. 3b). Because MTA1 enhances the invasion of HCC, we used transwell invasion assays to examine the effect of ER $\alpha$ on invasion. The invasive capacity of Hep3B-ER $\alpha$ cells was significantly lower than control cells (Fig. 3c). Specific shRNA targeting ER $\alpha$ knocked down endogenous ER $\alpha$ in HepG2 cells. ER $\alpha$ knockdown increased the proliferation of HepG2-shER $\alpha$ cells compared to control scramble-shRNA-treated cells (Fig. 3d). EdU assays indicated that ER $\alpha$ knockdown increased cell proliferation of HepG2-shER $\alpha$ cells (Fig. 3e). Matrigel invasion assays also demonstrated that ablation of endogenous ER $\alpha$ increased invasion by HepG2-shER $\alpha$ cells (Fig. 3f). Collectively, these results provided evidence that ER $\alpha$ expression was important for the aggressive phenotype of HCC cells. 
A

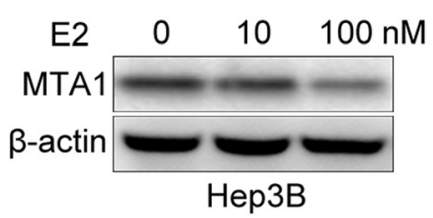

B

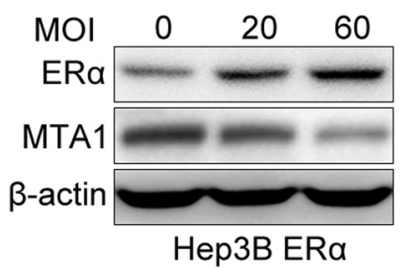

C

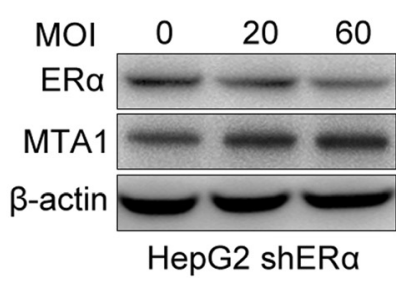

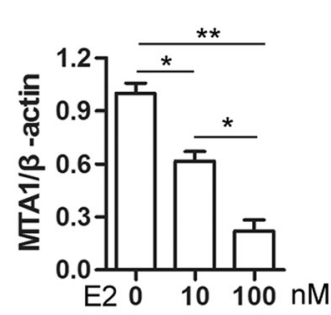
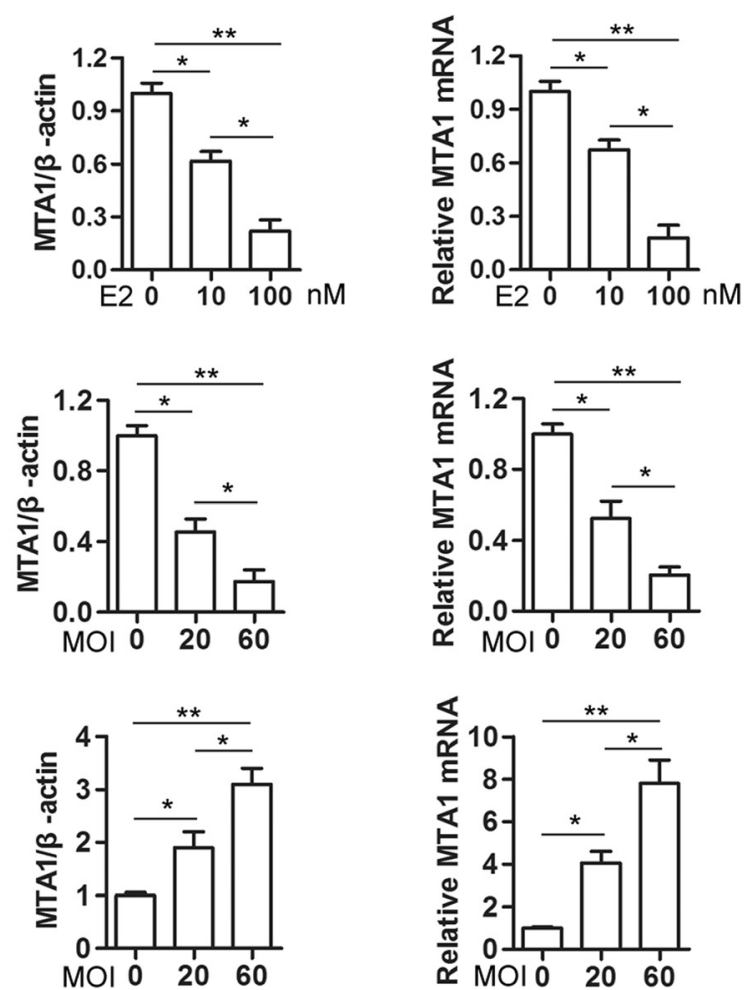

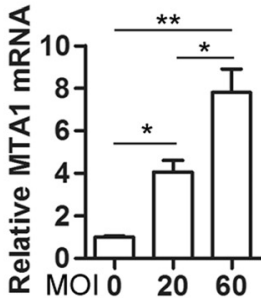

Fig. 2 ERa decreased MTA1 expression in HCC cells. a Hep3B cells were maintained in phenol red-free DMEM with $10 \%$ dextran-coated charcoal-treated FBS for $48 \mathrm{~h}$ and cells treated with either ethanol vehicle or E2 (10 or $100 \mathrm{nM})$ for $72 \mathrm{~h}$. Cells were harvested and analyzed for MTA1 mRNA (right) and protein. Results were from three independent experiments and presented as mean \pm SEM. $\mathbf{b}$ Western blot and real-time PCR analysis (right) for MTA1 protein and mRNA in Hep3B cells with MOI 20 or 60 ERa lentivirus infection. Results were from three independent experiments and presented as mean \pm SEM. c Western blot and real-time PCR analysis (right) for MTA1 protein and mRNA in HepG2 cells with MOI 20 or 60 for shRNA-ERa lentivirus infection $\left(n=3\right.$, mean \pm SEM) ${ }^{*} P<0.05$, ${ }^{*} P<0.01$ by $t$-test

Reestablishment of elevated MTA1 by ectopic expression abrogated ERa-mediated suppression of proliferation and invasion

MTA1 protein decreased in Hep3B-ER $\alpha$ cell lines in which ER $\alpha$ was ectopically overexpressed. To determine if ER $\alpha$ suppressed proliferation and invasion by reducing MTA1 expression, we constructed the cell line Hep3B-ER $\alpha$ / MTA1, which expressed ER $\alpha$ and ectopically overexpressed MTA1. Western blots showed that overexpression of MTA1 decreased expression of ER $\alpha$ in some Hep3BER $\alpha /$ MTA1 cells compared to Hep3B-ER $\alpha$ cells (Fig. 4a) with feedback regulation between ER $\alpha$ and MTA1. CCK- 8 and EdU assays demonstrated that MTA1 overexpression increased proliferation of Hep3B-ER $\alpha$ cells (Fig. 4b and c). Matrigel invasion assays showed that invasion of Hep3B-ER $\alpha$ cells significantly increased (Fig. 4d).

To test whether ER $\alpha$ overexpression decreased tumor formation by Hep3B cells, a subcutaneous injection model was established in BALB/c nude mice. At 4 weeks after injection of tumor cells, mice injected with Hep3B-ER $\alpha$ cells showed decreased tumor sizes compare to mice injected with Hep3B cells (Fig. 4e). Restoration of MTA1 expression resulted in significantly increased tumor sizes in Hep3B-ER $\alpha /$ MTA1 (Fig. 4e). These findings suggested that inhibition of MTA1 function by ER $\alpha$ impaired HCC proliferation and invasion.

\section{Discussion}

Previous studies on gender disparities in HCC highlight the linkage between oestrogen and inflammation-induced carcinogenesis [28]. Physiological doses of estrogen suppress HCC metastasis by decreasing interleukin-6 and hepatocyte growth factor expression in the tumor microenvironment [29]. MiR-18a prevents translation of ER, potentially blocking the protective effects of estrogen and promoting the development of HCC in women [11]. Elevated p53 promotes miR-18a processing to decrease ER $\alpha$ in HCC in women [30]. Oestrogen modulates HCC malignancy in vivo by reducing tumor cell invasion, arresting cell cycle progression, and promoting apoptosis, characterized by decreased expression of MMP-2, MMP-9, PCNA, cyclin A, cyclin D1, and Bcl-2, and increased expression of cleaved caspase 3. ER $\alpha$-mediated inhibition of NF-kappaB 

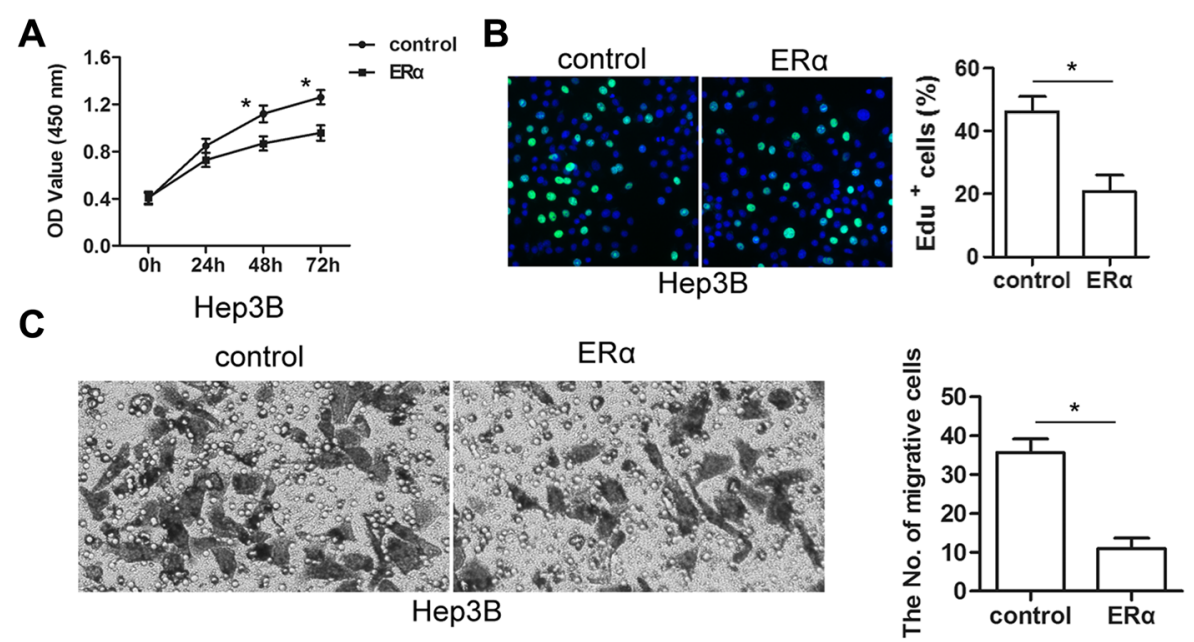

D

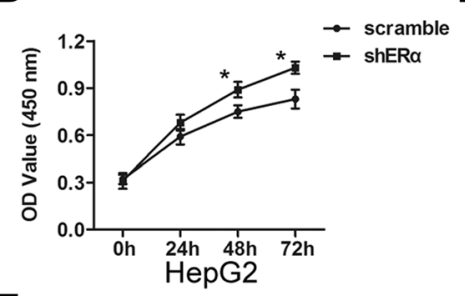

$\mathbf{F}$

E

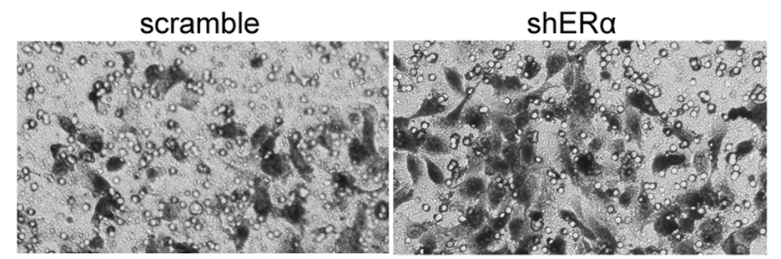

HepG2
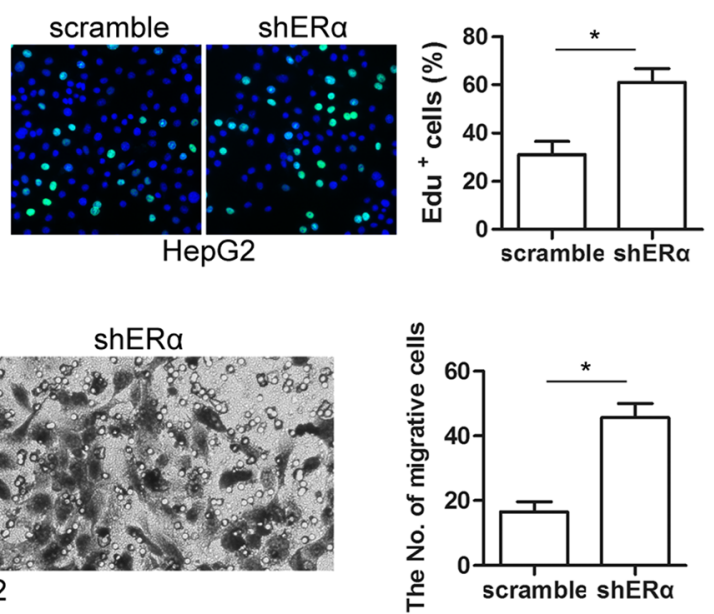

Fig. 3 ERa suppressed proliferation and invasion of HCC cells. a CCK-8 assays showed that overexpression of ERa inhibited Hep3B cell growth. Absorbance at $450 \mathrm{~nm}$ was measured. Results were from three independent experiments and presented as mean \pm SEM. b Bright cyan, EdU positive. EdU assays showed that ERa overexpression decreased the percent of EdU-positive in Hep3B cells compared to controls $(n=3$, mean \pm SEM). c Overexpression of ERa reduced invasion by Hep3B cells in transwell assays ( $n=3$, mean \pm SEM). $\mathbf{d}$ CCK-8 assays showed that knockdown of ERa increased HepG2 cell growth $(n=3$, mean \pm SEM). e Bright cyan, EdU-positive. EdU assays showed that ERa knockdown increased the percent of EdU-positive HepG2 cells compared to controls $(n=3$, mean \pm SEM). $\mathbf{f}$ Knockdown of ERa increased invasion by HepG2 cells in transwell assays $(n=3$, mean \pm SEM $) * P<0.05$ by $t$-test

binding is a pivotal event [23, 31]. Consistent with recent reports, we found that overexpression of ER $\alpha$ suppressed HCC proliferation and invasion and decreased MTA1 expression. In our previous study, we found that PTPRO expression results in pathological deficiency and gender bias in HCC, which could be attributed to ER $\alpha$ regulation [26]. Overexpression of miR-22 in male tumor adjacent tissue was associated with downregulated ER $\alpha$ expression, potentially by attenuating the protective effect of estrogen and causing increased IL- $1 \alpha$ expression [32] and STAT3 and IL- $1 \alpha$ involved in inflammation and stemness inducible of HCC progression. These mechanisms might be responsible of the in vivo effect of ERa on reduction of tumor growth in this study which could not be fully appreciated in the in vitro experiments on cell proliferation.

Transcriptional activation by ER $\alpha$ is a complex and multistep process that is influenced by coactivator and corepressor proteins that either positively or negatively modulate ER $\alpha$-mediated transcriptional activity $[21,33]$. The transcriptional activity of ER $\alpha$ is modified by coactivators, corepressors, and chromatin remodeling complexes. In our study, ER $\alpha$ was recruited to the MTA1 promoter chromatin to repress MTA1 promoter activity and downregulate MTA1 expression. Different ER $\alpha$ corepressors regulate steroid receptor activity through a variety of mechanisms, including formation of multiprotein 


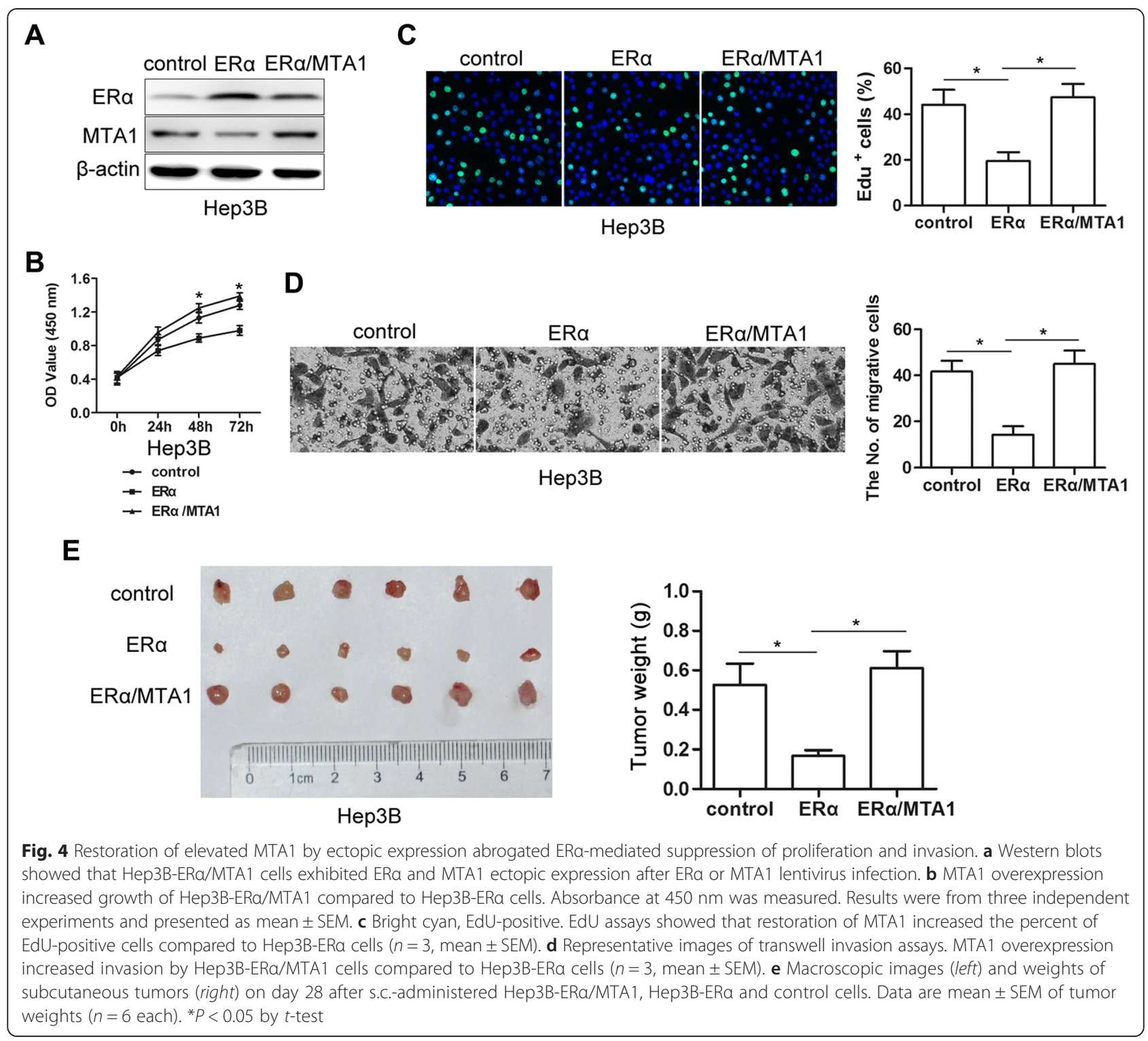

complexes that affect chromatin remodeling, histone deacetylation, or basal transcription [21]. Transcriptional repression, which is crucial for diverse biological processes, is mediated in part by non-DNA-binding corepressors [19]. Transcriptional repression by tamoxifen-bound ER at Eregulated gene promoters involves a dynamic interplay of multiple distinct chromatin-modifying and remodeling complexes [34]. Overexpression of ER $\alpha$ decreases PPAR $\gamma$ expression at the transcriptional and translational level in a ligand-dependent manner [35]. We hypothesized that expression of MTA1 would be determined by the level of $\mathrm{ER} \alpha$. Additionally, the ER $\alpha-\mathrm{SP} 1$ complex binds to the proximal and distal sites of the TNF $\alpha$ gene promoter and induces expression of active caspase three in a liganddependent manner [36]. ER $\alpha$ inhibits the epithelialmesenchymal transition by suppressing Bmil in breast cancer [37]. The N-terminus of NCOR2 interacts with other transcriptional corepressors to regulate transcription and its C-terminus binds to ER $\alpha$ [38]. The transcriptional corepressor TLE3 is recruited to chromatin by FoxA1 at several ER-binding sites throughout the genome. TLE3 mediates repression via interaction with HDACs to regulate histone acetylation [39]. Foxa factors have a dominant effect on gender specificity in HCC development, while Foxa-dependent ER $\alpha$ and AR have opposing effects in $\mathrm{HCC}$, with $\mathrm{ER} \alpha$-mediated estrogen signaling protective against HCC [40]. One of these mechanisms could be involved in regulation of MTA1.

MTA1 and MTA1s are corepressor proteins that act in different ways to prevent ER $\alpha$ transcriptional activity [41]. The shRNA targeted against MTA1 could specifically mediate the MTA1 gene silence and consequentially recover 
the protein expression of ER $\alpha$ [42]. MTA1-TFAP2C or the MTA1-IFI16 complex may contribute to the epigenetic regulation of ER $\alpha$ expression in breast cancer [43]. MTA1 and MICoA might transmodulate each other's functions. Any potential deregulation of MTA1 is likely to contribute to the functional inactivation of the ER pathway, presumably by derecruitment of MICoA from chromatin with ER promoter targets [44]. The MTA3 promoter has a functional ER element half-site and MTA3 gene regulation by $E R$ is influenced by dynamic changes in levels of nuclear coregulators, including MTA1 [45]. Overexpression of MTA1 resulted in a few Hep3B-ER $\alpha /$ MTA1 cells with decreased expression of ER $\alpha$ compared to Hep3B-ER $\alpha$ cell (Fig. 4a). Based on these results, feedback regulation between ER $\alpha$ and MTA1 might occur. This will be studied in our further research.

\section{Conclusions}

Our results showed that ER $\alpha$ suppressed proliferation and invasion of human HCC cells through transcriptional downregulation of MTA1. Our study is an improved description of the mechanisms of the suppressive effects of ER $\alpha$ on HCC and adds understanding to the gender disparity in HCC progression.

\begin{abstract}
Abbreviations
GAPDH: Glyceraldehyde 3-phosphate dehydrogenase; HCC: Hepatocellular carcinoma; IncRNA: Long non-coding RNAs; qRT-PCR: Quantitative real time polymerase chain reaction; SDS-PAGE: Sodium dodecyl sulphate polyacrylamide gel electrophoresis; $10 \%$ FBS: $10 \%$ fetal bovine serum; EDU: 5-ethynyl-2'-deoxyuridine.
\end{abstract}

\section{Competing interests}

The authors declared that they have no competing interest.

\section{Authors' contributions}

$\mathrm{RJ}$ and $\mathrm{BC}$ designed the study. HY and JT performed the experiments. AY and ZL drafted the manuscript. YG and XW supervised the experimental work. All authors read and approved the final manuscript.

\section{Authors' information}

RJ, MD, Ph.D, working in department of Liver Transplantation Center of The First Affiliated Hospital of Nanjing Medical University. He has worked for ten years as a scientific researcher.

\section{Acknowledgements}

This work was supported by grants from the National Natural Science Foundation (81201880 to LD, 81201528, 81572370 to RJ), Six talent peaks project in Jiangsu Province (WSW-020) to RJ, the National Natural Science Foundation for Distinguished Young Scholars (81225017 to B.S.), National Basic Research Program of China (2012CB910800 to B.S.).

\section{Author details}

'Liver Transplantation Center of the First Affiliated Hospital and State Key Laboratory of Reproductive Medicine, Nanjing Medical University, Nanjing, Jiangsu Province, P.R. China. ${ }^{2}$ Department of Hematology, The First Affiliated Hospital of Nanjing Medical University, Nanjing, Jiangsu Province, China.

Received: 16 September 2015 Accepted: 19 October 2015

Published online: 26 October 2015

\section{References}

1. Toh Y, Nicolson GL. The role of the MTA family and their encoded proteins in human cancers: molecular functions and clinical implications. Clin Exp Metastasis. 2009;26:215-27.

2. Hamatsu T, Rikimaru T, Yamashita Y, Aishima S, Tanaka S, Shirabe K, et al. The role of MTA1 gene expression in human hepatocellular carcinoma. Oncol Rep. 2003;10:599-604.

3. Ryu SH, Jang MK, Kim WJ, Lee D, Chung YH. Metastatic tumor antigen in hepatocellular carcinoma: golden roads toward personalized medicine. Cancer Metastasis Rev. 2014;33:965-80.

4. Song $Q$, Zhang $H$, Wang $M$, Song $W$, Ying $M$, Fang $Y$, et al. MTA1 promotes nasopharyngeal carcinoma growth in vitro and in vivo. J Exp Clin Cancer Res. 2013;32:54.

5. Li Y, Chao $Y$, Fang $Y$, Wang J, Wang $M$, Zhang $H$, et al. MTA1 promotes the invasion and migration of non-small cell lung cancer cells by downregulating miR-125b. J Exp Clin Cancer Res. 2013;32:33.

6. Moon WS, Chang K, Tarnawski AS. Overexpression of metastatic tumor antigen 1 in hepatocellular carcinoma: Relationship to vascular invasion and estrogen receptor-alpha. Hum Pathol. 2004;35:424-9.

7. Ryu SH, Chung YH, Lee H, Kim JA, Shin HD, Min HJ, et al. Metastatic tumor antigen 1 is closely associated with frequent postoperative recurrence and poor survival in patients with hepatocellular carcinoma. Hepatology. 2008;47:929-36.

8. Jin YJ, Chung YH, Kim JA, Park WH, Lee D, Seo DD, et al. Factors predisposing metastatic tumor antigen 1 overexpression in hepatitis B virus associated hepatocellular carcinoma. Dig Dis Sci. 2012;57:2917-23.

9. Shimizu I, Inoue H, Yano M, Shinomiya H, Wada S, Tsuji Y, et al. Estrogen receptor levels and lipid peroxidation in hepatocellular carcinoma with hepatitis C virus infection. Liver. 2001;21:342-9.

10. lavarone M, Lampertico P, Seletti C, Francesca Donato M, Ronchi G, del Ninno $E$, et al. The clinical and pathogenetic significance of estrogen receptor-beta expression in chronic liver diseases and liver carcinoma. Cancer. 2003;98:529-34.

11. Liu WH, Yeh SH, Lu CC, Yu SL, Chen HY, Lin CY, et al. MicroRNA-18a prevents estrogen receptor-alpha expression, promoting proliferation of hepatocellular carcinoma cells. Gastroenterology. 2009;136:683-93.

12. Han J, Ding L, Yuan B, Yang X, Wang X, Li J, et al. Hepatitis B virus X protein and the estrogen receptor variant lacking exon 5 inhibit estrogen receptor signaling in hepatoma cells. Nucleic Acids Res. 2006;34:3095-106.

13. Yu MW, Chang HC, Chang SC, Liaw YF, Lin SM, Liu CJ, et al. Role of reproductive factors in hepatocellular carcinoma: Impact on hepatitis B- and C-related risk. Hepatology. 2003;38:1393-400.

14. Nakatani T, Roy G, Fujimoto N, Asahara T, Ito A. Sex hormone dependency of diethylnitrosamine-induced liver tumors in mice and chemoprevention by leuprorelin. Jpn J Cancer Res. 2001;92:249-56.

15. $\mathrm{Ng} \mathrm{IO,} \mathrm{Ng} \mathrm{M,} \mathrm{Fan} \mathrm{ST.} \mathrm{Better} \mathrm{survival} \mathrm{in} \mathrm{women} \mathrm{with} \mathrm{resected} \mathrm{hepatocellular}$ carcinoma is not related to tumor proliferation or expression of hormone receptors. Am J Gastroenterol. 1997;92:1355-8.

16. Jonas S, Bechstein WO, Heinze T, Kling N, Lobeck H, Tullius SG, et al. Female sex hormone receptor status in advanced hepatocellular carcinoma and outcome after surgical resection. Surgery. 1997;121:456-61.

17. Nagasue N, Kohno H, Chang YC, Yamanoi A, Nakamura T, Yukaya H, et al. Clinicopathologic comparisons between estrogen receptor-positive and -negative hepatocellular carcinomas. Ann Surg. 1990;212:150-4.

18. Yeh SH, Chen PJ. Gender disparity of hepatocellular carcinoma: the roles of sex hormones. Oncology. 2010;78 Suppl 1:172-9.

19. Jepsen K, Rosenfeld MG. Biological roles and mechanistic actions of co-repressor complexes. J Cell Sci. 2002;115:689-98.

20. Zhou X, Wang X, Huang Z, Xu L, Zhu W, Liu P. An ER-associated miRNA signature predicts prognosis in ER-positive breast cancer. J Exp Clin Cancer Res. 2014;33:94

21. Dobrzycka KM, Townson SM, Jiang S, Oesterreich S. Estrogen receptor corepressors - a role in human breast cancer? Endocr Relat Cancer. 2003;10:517-36.

22. Klinge CM. Estrogen receptor interaction with co-activators and co-repressors. Steroids. 2000;65:227-51.

23. Sheng ML, Xu GL, Zhang CH, Jia WD, Ren WH, Liu WB, et al. Aberrant estrogen receptor alpha expression correlates with hepatocellular carcinoma metastasis and its mechanisms. Hepatogastroenterology. 2014;61:146-50.

24. Lin RJ, Nagy L, Inoue S, Shao W, Miller Jr WH, Evans RM. Role of the histone deacetylase complex in acute promyelocytic leukaemia. Nature. 1998;391:811-4. 
25. Liang K, Yang L, Yin C, Xiao Z, Zhang J, Liu Y, et al. Estrogen stimulates degradation of beta-amyloid peptide by up-regulating neprilysin. J Biol Chem. 2010;285:935-42.

26. Hou J, Xu J, Jiang R, Wang Y, Chen C, Deng L, et al. Estrogen-sensitive PTPRO expression represses hepatocellular carcinoma progression by control of STAT3. Hepatology. 2013;57:678-88.

27. Zhang Z, Zhang Y, Sun XX, Ma X, Chen ZN. microRNA-146a inhibits cancer metastasis by downregulating VEGF through dual pathways in hepatocellular carcinoma. Mol Cancer. 2015;14:5.

28. Xin G, Qin S, Wang S, Wang X, Zhang Y, Wang J. Sex hormone affects the severity of non-alcoholic steatohepatitis through the MyD88-dependent IL-6 signaling pathway. Exp Biol Med (Maywood). 2015. [Epub ahead of print]

29. Wang YC, Xu GL, Jia WD, Han SJ, Ren WH, Wang W, et al. Estrogen suppresses metastasis in rat hepatocellular carcinoma through decreasing interleukin-6 and hepatocyte growth factor expression. Inflammation. 2012;35:143-9.

30. Li CL, Yeh KH, Liu WH, Chen CL, Chen DS, Chen PJ, et al. Elevated p53 promotes the processing of miR-18a to decrease estrogen receptor-alpha in female hepatocellular carcinoma. Int J Cancer. 2015;136:761-70.

31. Xu H, Wei Y, Zhang Y, Xu Y, Li F, Liu J, et al. Oestrogen attenuates tumour progression in hepatocellular carcinoma. J Pathol. 2012;228:216-29.

32. Jiang $R$, Deng $L$, Zhao L, Li X, Zhang F, Xia Y, et al. miR-22 promotes HBVrelated hepatocellular carcinoma development in males. Clin Cancer Res. 2011;17:5593-603.

33. Madhavan S, Gusev Y, Singh S, Riggins RB. ERRgamma target genes are poor prognostic factors in Tamoxifen-treated breast cancer. J Exp Clin Cancer Res. 2015;34:45

34. Liu XF, Bagchi MK. Recruitment of distinct chromatin-modifying complexes by tamoxifen-complexed estrogen receptor at natural target gene promoters in vivo. J Biol Chem. 2004;279:15050-8.

35. Lin YM, Velmurugan BK, Yeh YL, Tu CC, Ho TJ, Lai TY, et al. Activation of estrogen receptors with E2 downregulates peroxisome proliferator-activated receptor gamma in hepatocellular carcinoma. Oncol Rep. 2013;30:3027-31.

36. Tu CC, Kumar VB, Day CH, Kuo WW, Yeh SP, Chen RJ, et al. Estrogen receptor alpha (ESR1) over-expression mediated apoptosis in Hep3B cells by binding with SP1 proteins. J Mol Endocrinol. 2013;51:203-12.

37. Wei XL, Dou XW, Bai JW, Luo XR, Qiu SQ, Xi DD, et al. ERalpha inhibits epithelial-mesenchymal transition by suppressing Bmi1 in breast cancer. Oncotarget. 2015. [Epub ahead of print]

38. Zhang L, Gong C, Lau SL, Yang N, Wong OG, Cheung AN, et al. SpliceArray profiling of breast cancer reveals a novel variant of NCOR2/SMRT that is associated with tamoxifen resistance and control of ERalpha transcriptional activity. Cancer Res. 2013;73:246-55.

39. Jangal M, Couture JP, Bianco S, Magnani L, Mohammed H, Gevry N. The transcriptional co-repressor TLE3 suppresses basal signaling on a subset of estrogen receptor alpha target genes. Nucleic Acids Res. 2014;42:11339-48.

40. Zhao Y, Li Z. Interplay of estrogen receptors and FOXA factors in the liver cancer. Mol Cell Endocrinol. 2015. [Epub ahead of print]

41. Acconcia F, Kumar R. Signaling regulation of genomic and nongenomic functions of estrogen receptors. Cancer Lett. 2006;238:1-14.

42. Jiang $Q$, Zhang $H$, Zhang P. ShRNA-mediated gene silencing of MTA1 influenced on protein expression of ER alpha, MMP-9, CyclinD1 and invasiveness, proliferation in breast cancer cell lines MDA-MB-231 and MCF-7 in vitro. J Exp Clin Cancer Res. 2011;30:60.

43. Kang HJ, Lee MH, Kang HL, Kim SH, Ahn JR, Na H, et al. Differential regulation of estrogen receptor alpha expression in breast cancer cells by metastasis-associated protein 1. Cancer Res. 2014;74:1484-94.

44. Mishra SK, Mazumdar A, Vadlamudi RK, Li F, Wang RA, Yu W, et al. MICoA, a novel metastasis-associated protein 1 (MTA1) interacting protein coactivator, regulates estrogen receptor-alpha transactivation functions. J Biol Chem. 2003;278:19209-19.

45. Mishra SK, Talukder AH, Gururaj AE, Yang Z, Singh RR, Mahoney MG, et al. Upstream determinants of estrogen receptor-alpha regulation of metastatic tumor antigen 3 pathway. J Biol Chem. 2004;279:32709-15.

\section{Submit your next manuscript to BioMed Central and take full advantage of:}

- Convenient online submission

- Thorough peer review

- No space constraints or color figure charges

- Immediate publication on acceptance

- Inclusion in PubMed, CAS, Scopus and Google Scholar

- Research which is freely available for redistribution

Submit your manuscript at www.biomedcentral.com/submit 